Session 2005

\title{
Engaging Students in Multidisciplinary Engineering Problem Solving: An Investigation of an Airflow Imbalance and Humidification Problem at an Absorbent Hygiene Production Facility
}

\author{
Robert Choate, Kevin Schmaltz, Rod Handy, Jason Arterburn, Joey Willcox \\ Western Kentucky University/Purdue University
}

\begin{abstract}
An investigation of an airflow imbalance and humidification problem was recently conducted at an absorbent hygiene manufacturing location in the southern US. The project's multidisciplinary approach involved a student engagement team of one senior mechanical engineering student and one graduate student in environmental science, as well as two mechanical engineering faculty members and an environmental science faculty member. The students participated in all phases of the project from initial site visit to report completion and follow-up.

The facility of concern manufactured a fluff pulp and super absorbent polymer product. To assure product quality, a relative humidity range between 30 and 50 percent was required. Relative humidity conditions well above the 50\% maximum value were experienced during the summer months due to a significant negative pressure differential induced by process equipment inside the facility. A quantification of the problem and potential solutions were sought to provide better overall control of the facility relative humidity and subsequent product quality.
\end{abstract}

The student team collected the majority of the field data during a two-month period in the late summer and early fall using an air velocity meter and a Pitot traverse tube to determine volumetric airflow, a standard indoor air quality meter to record temperature and relative humidity, and a differential pressure instrument to measure indoor and outdoor pressure differences. Significant points of possible air infiltration were quantitatively evaluated as well as HVAC, process supply and exhaust air ductwork.

After the data collection was completed, an air mass balance was performed, and the results were compared with approximations supplied by HVAC and process equipment suppliers. Overall air deficit calculations resulted in a negative volumetric flow range of 75,000 to 125,000 CFM, depending upon the operating conditions existing inside the plant. Significant points of air infiltration were assessed and included fork truck overhead doors and employee doorways.

It was concluded that a reduction in the negative pressure differential was imperative to proper humidity control. The recommendation for accomplishing this included a long-term solution of filtering and returning the process air back into the manufacturing space.

"Proceedings of the 2005 American Society for Engineering Education Annual Conference \& Exposition Copyright (c) 2005, American Society for Engineering Education” 
Student involvement in this project was critical to its success. They participated in all of the meetings, collected the field data, evaluated the results, and assisted in the preparation of the final report. The benefits to the various parties involved in this multidisciplinary, student engagement activity were several-fold. The students gained practical experiences in analytical problem solving; the company received a high quality, economical assessment of their problem, and the professors gained experiences that could be shared with other students in the classroom.

\section{Introduction}

This study involved the investigation of an airflow imbalance and humidification problem at an adult hygiene production facility. The product of concern consists of a highly absorbent fluff pulp material and super absorbent polymer, and to assure product quality it is necessary to maintain manufacturing space conditions from $30 \%$ to $50 \%$ relative humidity. During the summer of 2003, humidity levels in this facility exceeded the 50\% limit. In August of 2003, a team of faculty and student researchers was asked to perform an analysis and propose recommendations to the humidity control problem in this facility's manufacturing area.

Initial discussions indicated that during the summer months when the relative humidity exceeded the desired range, the excess moisture in the air caused the super absorbent polymer and the fluff pulp to begin to gel. As the products begin to gel, there is a subsequent buildup on the drum formers of equipment presses causing incorrect product formation. Engineering managers at the facility suggested that a negative air balance in the manufacturing area, which they estimated to be around 80,000 CFM, could cause part of the problem. The net air imbalance is the difference between production system exhaust and HVAC inflow into the manufacturing area.

It was noted initially from management that they were in the process of reducing the negative air balance to approximately 60,000 CFM. This was being accomplished by returning 20,000 CFM from a reclamation system to the manufacturing space. Management was considering the possibility of further reducing the negative air balance problem to approximately 20,000 CFM by a proposal from an HVAC contractor to add 200 tons of additional cooling, which will provide 40,000 CFM of additional external air to the facilities.

\section{Data Collection}

Data was collected at this facility for approximately three months for temperature, relative humidity, airflow imbalance, and differential pressures. A graduate student, adept in environmental sampling and monitoring, guided an undergraduate student with cooperative experiences at the facility in the data gathering phase of this assessment. The following sections provide the details.

\section{Temperature and Relative Humidity Measurements}

The relative humidity was recorded within the manufacturing space at three locations where stationary humidity monitors already exist. An average reading by existing equipment of $61.2 \%$ relative humidity compared to average readings of $57.3 \%$ by measurement equipment brought in

"Proceedings of the 2005 American Society for Engineering Education Annual Conference \& Exposition Copyright (c) 2005, American Society for Engineering Education” 
by the team - a discrepancy of $2.9 \%$ relative humidity (or an error of $6.8 \%$ ). Combined temperature and relative humidity measurements were also made at one location over a 15 -hour period. These results varied from $75^{\circ} \mathrm{F}$ to $78^{\circ} \mathrm{F}$ and the relative humidity ranged from $56 \%$ to $62 \%$. The measurements clearly corroborated the claim that the manufacturing space conditions were outside of the target maximum value of $50 \%$ relative humidity.

\section{Airflow Imbalance Measurements}

To improve the potential air imbalance estimate, major sources of the inflow supply and outflow exhaust air were quantified through measurement or technical specification. Supply air is delivered to the conditioned space and used for ventilation, heating, cooling, humidification or dehumidification. Table 1 provides a volumetric airflow summary for the specific site inflows and outflows.

Management provided the manufacturer estimated airflow data for the air handling units (AHU), which were being used to estimate the outflow from the manufacturing space. Since the discharge ducts of the AHUs ducts were accessible on the roof of the manufacturing space, an effort was made to verify the accuracy of the manufacturer estimated exhaust air volume for each production line AHU. The student team measured the air velocities with a Pitot tube in four of the six AHUs using a Pitot tube traverse method outlined by the American Conference of Governmental Industrial Hygienists (ACGIH) ${ }^{1}$. The comparison of this data is presented in Table 1, which only shows Production Line 1. Lines 1 and 2 cannot be operated at the same time; it is assumed that the flow rate would be same for both. Based on the results from our investigations, the net throughput of air from all of the AHUs is closer to 200,000 CFM than the 150,000 CFM manufacturer's combined estimates.

The typical operation of the rooftop air conditioners is $85 \%$ recirculated air and $15 \%$ makeup (outside) air. Recirculated air is removed from the conditioned space but immediately reused as supply air. It differs from return air only in that some of the return air may be exhausted or relieved through dampers or by fans. Makeup air is outdoor air supplied to replace exhaust air and exfiltration. The other inflow air source is the ground-mounted air conditioner, which operates using $100 \%$ makeup (outside) air.

Due to safety and accessibility issues, it was not possible for the student team to verify the incoming airflow rates from the six rooftop ACUs or the ground-mounted ACU directly, and so the manufacturer's estimates were used. During some of the data gathering in the fall, the settings of the rooftop ACUs were changed to $50 \%$ outside air to create a greater inflow. Table 2 above summarizes these flow rates.

Therefore, the maximum outside air supply volume can be calculated as follows:

6 rooftop ACUs@3,975 CFM + 1 ground-mounted ACU @ 50,000 CFM=73,850 CFM 
Based on these measurements, the overall estimate of maximum net airflow from the manufacturing space will be between 74,150 CFM (148,000 CFM out - 73,850 CFM in) and 123,950 CFM (197,800 CFM out - 73,850 CFM in). This will be discussed in a subsequent section.

Table 1: Air Handing Units for Production Lines Volumetric Airflow Summary

\begin{tabular}{|c|c|c|l||}
\hline $\begin{array}{c}\text { Manufacturing } \\
\text { Line }\end{array}$ & $\begin{array}{c}\text { Manufacturer } \\
\text { Estimated Volumetric } \\
\text { Airflow (CFM) }\end{array}$ & $\begin{array}{c}\text { Student Measured } \\
\text { Volumetric Airflow } \\
\text { (CFM) }\end{array}$ & $\begin{array}{l}\text { Comments/ Measurement } \\
\text { Method }\end{array}$ \\
\hline \hline Line1 & 21,000 & 26,500 & $\begin{array}{l}\text { ACGIH Pitot traverse } \\
\text { method used }\end{array}$ \\
\hline Line 3 & 28,000 & 33,400 & $\begin{array}{l}\text { Due to accessibility, } \\
\text { assumed comparable to } \\
\text { Line 4 }\end{array}$ \\
\hline Line 4 & 28,000 & 33,400 & $\begin{array}{l}\text { ACGIH Pitot traverse } \\
\text { method used }{ }^{1}\end{array}$ \\
\hline Line 6 & 23,000 & 29,700 & $\begin{array}{l}\text { ACGIH Pitot traverse } \\
\text { method used }{ }^{1}\end{array}$ \\
\hline Line 7 & 28,000 & 28,000 & $\begin{array}{l}\text { Due to accessibility, } \\
\text { manufactured data assumed }\end{array}$ \\
\hline Reclamation & 20,000 & 46,800 & $\begin{array}{l}\text { ACGIH Pitot traverse } \\
\text { method used }{ }^{1}\end{array}$ \\
\hline \hline TOTAL & $\mathbf{1 4 8 , 0 0 0}$ & $\mathbf{1 9 7 , 8 0 0}$ & Difference of 49,800 \\
\hline
\end{tabular}

Table 2: Air Condition Unit: Air Handling Units Volumetric Airflow Summary

\begin{tabular}{||l|c|c|c||}
\hline \hline ACU / Operating Condition & $\begin{array}{c}\text { Total Supply } \\
\text { Volumetric } \\
\text { Airflow (CFM) }\end{array}$ & $\begin{array}{c}\text { Return } \\
\text { Volumetric } \\
\text { Airflow (CFM) }\end{array}$ & $\begin{array}{c}\text { Positive Volumetric } \\
\text { Airflow (CFM) }\end{array}$ \\
\hline \hline $\begin{array}{l}\text { Rooftop ACU: AHU @ 50\% } \\
\text { Outside Air }\end{array}$ & 26,500 & 13,250 & 13,250 \\
\hline $\begin{array}{l}\text { Rooftop ACU: AHU in } \\
\text { Economizer Mode @ 15\% } \\
\text { Outside Air }\end{array}$ & 26,500 & 22,525 & 3,975 \\
\hline $\begin{array}{l}\text { Ground-Mounted ACU: AHU } \\
@ 100 \% \text { Outside Air }\end{array}$ & 50,000 & 0 & 50,000 \\
\hline $\begin{array}{l}\text { Ground-Mounted ACU: AHU } \\
\text { @ 100\% Outside Air }\end{array}$ & 50,000 & 25,000 & 25,000 \\
\hline
\end{tabular}

"Proceedings of the 2005 American Society for Engineering Education Annual Conference \& Exposition Copyright (c) 2005, American Society for Engineering Education” 


\section{Differential Pressure Measurements}

Over 3 days, differential pressure between the manufacturing space and the outside was recorded while different combinations of AHUs of the production systems and the settings of the ACUs were generated. This experiment allowed for the characterization of the relationship between the differential pressure and the net airflow deficit. Differential pressures were measured by the student team at 15 locations within the manufacturing space. Average differential pressures with respect to outside conditions are summarized in Table 3.

By altering the operation of the AHUs and the ACUs systems, differential pressures from 0.023 " of water to 0.190 " of water were achieved. Using the airflow estimates calculated earlier for each system, these differential pressures were achieved under air balance deficits between 62,550 CFM and 197,800 CFM.

Table 3: Building Differential Pressure versus Airflow Deficit

\begin{tabular}{|c|c|c|}
\hline \multicolumn{3}{|c|}{ Manufacturing Space Differential Pressure } \\
\hline $\begin{array}{c}\text { Differential Pressure } \\
\text { (Inches of H2O) }\end{array}$ & Equipment Settings & $\begin{array}{c}\text { Estimated Airflow Deficit } \\
\text { (CFM) }\end{array}$ \\
\hline 0.023 ” & Minimum Negative & 62,550 \\
\hline 0.147 ” & Normal Operating & 123,950 \\
\hline $0.190 ”$ & Maximum Negative & 197,800 \\
\hline
\end{tabular}

\section{Summary and Discussion}

The data presented warrants discussion in two primary areas: airflow data and differential pressure data. The airflow balance represents the source of the humidity problem in the manufacturing space during summer months. The differential pressure data is the driving force behind this airflow. In the following section, the results from the data collection are analyzed.

\section{Air Mass Balance Analysis}

In this section, the results of the findings of the estimated magnitude of deficit air mass balance and the potential operational conditions within the manufacturing space will be discussed. The typical facility HVAC design rule is that there should be a balance between the amount of air entering and the amount of air leaving a space ${ }^{2,3}$. Due to the high volume of air required by the production process at the site, balancing the air mass entering and leaving the entire manufacturing space is currently impossible. The range of overall air balance deficit is from 74,150 CFM to 123,950 CFM, detailed in Table 4. 
The two approaches to solve the airflow imbalance and avoid the potential for infiltration of unconditioned air is to either: (1) filter and return all production system exhaust air and adjust the ACUs to condition manufacturing space to meet process control and human comfort requirements, or (2) increase the capacity of the AHUs of the ACUs of the manufacturing space to match the negative airflow volume with conditioned outside air. It will not be possible to eliminate the humidity problem by controlling air infiltration through doors, as will be discussed in a subsequent section.

Table 4: Manufacturing Space Air Mass Balance Deficit

\begin{tabular}{||c|c|c|c||}
\hline $\begin{array}{c}\text { Outflow Estimate } \\
\text { by: }\end{array}$ & $\begin{array}{c}\text { Outflow Estimate } \\
\text { (CFM) }\end{array}$ & $\begin{array}{c}\text { Maximum Inflow } \\
\text { Estimate (CFM) }\end{array}$ & $\begin{array}{c}\text { Resulting Air Balance } \\
\text { Deficit (CFM) }\end{array}$ \\
\hline \hline Manufacturer & 148,000 & 73,850 & 74,150 \\
\hline WKU Students & 197,800 & 73,850 & 123,950 \\
\hline
\end{tabular}

\section{Differential Air Pressure Analysis}

The air mass imbalance causes a pressure difference between the inside and outside of the manufacturing space. This pressure difference is readily noted when entering the space, and the door slams behind manufacturing personnel after entry. Also, significant infiltration airflow velocity is evident in the large passageways and doorways leading into the manufacturing space from adjacent raw materials, maintenance shop and finished goods spaces. A major issue with this imbalance air condition is the infiltration of outside air at unacceptable moisture content levels. In order to estimate the severity of the problem, differential pressure measurements were performed around the perimeter of the manufacturing space under a range of manufacturing space operational conditions.

Based on the differential pressure, the infiltration rate into the manufacturing space was estimated using two methods: the air change method and the crack method ${ }^{4}$. The crack method is generally considered to be the most accurate when the crack and pressure characteristics can be properly evaluated. In this investigation, the pressure differential between the inside and outside of the manufacturing space was measured, and therefore, known under various operating conditions of the ACUs and AHUs of the production systems. However, the accuracy of predicting air infiltration is restricted by the limited information on the air leakage characteristics of the many components: walls, doors, windows, and roofing systems, that makeup the structure. Due to the scope of this paper, the details of these methods and subsequent results will not be elucidated at this time.

\section{Local Airflow Analysis}

The estimations inferred by the calculations for the infiltration rate and differential pressures revealed that a negative pressure, resulting from an imbalance between production systems outflow and ACU inflow, is only partially accounted for by infiltration through building wall and ceiling leaks. The larger portion of this infiltration will come from large airflows in certain areas, such as doors or other building openings. This is presented in Table 5, where under normal operating conditions a deficit air balance of 123,950 CFM exists. The differential pressure caused by this deficit creates an infiltration of 34,000 CFM through the walls and roof

"Proceedings of the 2005 American Society for Engineering Education Annual Conference \& Exposition Copyright (c) 2005, American Society for Engineering Education” 
of the building. The remaining inflow of 89,950 CFM $(123,950$ - 34,000) must occur through larger openings such as doors and passageways connected to unconditioned space.

Table 5: Comparison of Building Infiltration Under Operating Conditions

\begin{tabular}{|c|c|c|c||}
\hline $\begin{array}{c}\text { Air Balance } \\
\text { Estimate } \\
(\mathbf{C F M})\end{array}$ & $\begin{array}{c}\text { Differential } \\
\text { Pressure } \\
\left(\text { Inches of } \mathbf{H}_{\mathbf{2}} \mathbf{O}\right)\end{array}$ & $\begin{array}{c}\text { Wall/Ceiling Inflow } \\
\text { Estimate } \\
\text { (CFM) }\end{array}$ & $\begin{array}{c}\text { Doors/Openings Inflow } \\
\text { Estimate } \\
\text { (CFM) }\end{array}$ \\
\hline 123,950 & 0.147 & 34,000 & 89,950 \\
\hline
\end{tabular}

The implication behind this is that while average manufacturing space conditions might meet or approach desired conditions, it is possible with these strong local airflows of untreated air to have conditions in areas of the manufacturing space that are far from desired.

The infiltration from the single bank of doors under a differential pressure of 0.147 inches of water at a rate of 20 people per hour is estimated at 3000 CFM. An estimate of infiltration for the fork truck traffic was obtained by directly measuring the velocities across the door space. Measurements were taken during a period of down time in the manufacturing and were obtained under the maximum positive airflow volume condition $(129,500 \mathrm{CFM})$, which resulted in a measured differential pressure of 0.076 inches of water. This condition is slightly less severe than the maximum negative airflow condition (123,950 CFM at 0.147 inches of water). Under this maximum positive airflow condition, the average velocity of the air exiting the manufacturing space through the door opening was measured to be $400 \mathrm{ft} /$ minute. Applied over the fork truck door area of $126 \mathrm{ft}^{2}$, the potential infiltration is estimated at 50,400 CFM.

The fork truck doors were also timed to remain open for a measured period of 17 seconds, which would allow only $14,300 \mathrm{ft}^{3}$ of unconditioned air to enter the manufacturing space. It is estimated that the four doors of this type leading from adjacent spaces open between 25 and 35 times an hour. Therefore, the impact due to the infiltration through these door openings could be significant and range from $357,500 \mathrm{ft}^{3}$ to $500,500 \mathrm{ft}^{3}$ of unconditioned air entering from the raw materials, maintenance and finished goods spaces.

\section{Recommendations}

The results in the previous section lead to two possible approaches to solve the humidity problem within the manufacturing space; overall air infiltration control or localized climate control. To eliminate the infiltration of untreated outside air, it would be necessary to create a slight pressurization of the indoor space. This would be accomplished by introducing more conditioned outside air into the manufacturing space than is exhausted by the AHUs of the production systems. The manufacturing space is depressurized by the consequence of the production process, which exhausts between 75,000 CFM and 125,000 CFM more than the current ACUs can replace. This is undesirable from an indoor air quality and humidity control perspective.

One approach to solve this issue is to pressurize the space to avoid infiltration. Improve filtering and return the production systems exhaust air into the manufacturing space can accomplish this approach. The ACUs and their AHUs would have to be adjusted to properly condition the

"Proceedings of the 2005 American Society for Engineering Education Annual Conference \& Exposition Copyright (c) 2005, American Society for Engineering Education” 
manufacturing air space and maintain a slight positive pressure. The production systems discharge temperature is approximately $100^{\circ} \mathrm{F}$, which is greater than the outside temperature even during the hottest summer periods. This would increase the load for the ACUs, but could be balanced by reducing the current ACU load below its current $100 \%$ external air setting.

Alternatively, something short of completely rerouting all AHU of the production systems air discharges back into the plant could also solve the humidity problem. If several discharges were filtered and returned to the plant, this would reduce the current 75,000 CFM to 125,000 CFM air balance deficit. It would be necessary to reduce the deficit to approximately 50,000 CFM in order to achieve an average relative humidity level of about $50 \%$. The main focus of this investigation has been to characterize the overall situation and develop average property data that could be applied over the entire manufacturing space. It is also possible to control the humidity problem at a local level. The humidity only needs to be below 50\% near the operating lines. The strong influence of untreated air entering the facility through open doors will create areas with much higher than average relative humidity.

To reduce the infiltration due to people and fork truck traffic, administrative controls could be imposed to limit access from the office space or break area into the manufacturing space through the vestibule type door only, which forms an air lock between the adjacent office and the manufacturing spaces. Under the conditions outlined above to estimate infiltration through single bank doors, the same approach and conditions would yield no infiltration through a vestibule type door. In addition, curtain screens should be installed in the fork truck doors. These screens can significantly reduce the potential infiltration of unconditioned air if the manufacturing space cannot be maintained at a positive pressure or to reduce impact of the exfiltration of conditioned air under positive pressure conditions to reduce the cost of operations for the ACUs to maintain indoor air quality for process control and human comfort.

\section{Conclusions:}

Several lessons were learned from this investigation. Difficulties were encountered in scheduling site visits to collect data and conduct walkthroughs. Team member's obligations made it nearly impossible to allow for a comprehensive, team approach to completing the necessary fieldwork. In order to keep on a realistic time schedule, while difficult, it was found imperative to meet regularly as a team. Due to other responsibilities, the overall process was quite taxing on both the students and the faculty.

And, with respect to the student involvement in this project, it was determined at the onset that project success would rely heavily upon student technical capabilities and willingness to meet deadlines as set forth. Thus, it was felt that the students should participate in every aspect of the project. They were present and active during the initial meetings and collected most of the project data. The project team met extensively during the time period and each meeting included a project update provided by the students. In addition, the students assisted in the writing of the final project report. Overall, the efforts of the students contributed significantly to the success of this project.

"Proceedings of the 2005 American Society for Engineering Education Annual Conference \& Exposition Copyright (C) 2005, American Society for Engineering Education" 
In conclusion, the successes well outnumbered the failures encountered in this multidimensional problem solving approach. The winners were three-fold. The company received an economical, comprehensive assessment of their problem, the students gained "hands-on" experiences in problem solving, and the faculty realized experiences that they could take back to the classroom.

\section{Bibliography:}

1. ACGIH. 2001. Industrial ventilation: a manual of recommended practice, $24^{\text {th }}$ Ed.. Cincinnati: American Conference of Governmental Industrial Hygienists.

2. ASHRAE. 1997. ASHRAE handbook, fundamentals volume. Atlanta: American Society of Heating, Refrigeration and Air-Conditioning Engineers, Inc.

3. ASHRAE. 1995. 1995 ASHRAE handbook-HVAC applications, Chapter 12. Atlanta: American Society of Heating, Refrigerating and Air-Conditioning Engineers, Inc.

4. ASHRAE. 1992. ASHRAE cooling and heating load calculation manual, $2^{\text {nd }}$ Ed. Atlanta: American Society of Heating, Refrigerating and Air-conditioning Engineers, Inc.

\section{ROBERT CHOATE}

Robert Choate teaches thermo-fluid and professional component courses in Mechanical Engineering, including the Sophomore Design, Junior Design, the Senior ME Lab I and the ME Senior Project Design course sequence. Prior to teaching at WKU, he was a principal engineer for CMAC Design Corporation, designing telecommunication, data communication and information technology equipment.

\section{KEVIN SCHMALTZ}

Kevin Schmaltz teaches thermo-fluid and professional component courses in Mechanical Engineering, including the Freshman Experience course, Sophomore Design, Junior Design and the Senior Project Design course sequence. Prior to teaching at WKU, he was a project engineer for Shell Oil, designing and building oil and gas production facilities for offshore platforms in the Gulf of Mexico.

\section{ROD HANDY}

Rod Handy teaches manufacturing processes and polymeric materials and processes in the Department of Mechanical Engineering Technology at Purdue University. Prior to coming to Purdue, he was faculty member at Western Kentucky University for eight years and a manufacturing engineer with Ford Motor Company for five years.

\section{JASON ARTERBURN}

Jason Arterburn was a Mechanical Engineering undergraduate student when this investigation was undertaken. He received his Bachelor of Science Degree in Mechanical Engineering in May 2004 at Western Kentucky University.

\section{JOEY WILLCOX}

Joey Willcox was a graduate student in the Department of Public Health when this investigation was undertaken. He received his Bachelor of Science Degree in Environmental Science - Industrial Hygiene option in May 2003 at Western Kentucky University and is currently employed as an environmental consultant with Ensafe in Bowling Green, KY. 